\title{
The Course of Psychopathologic Features in Mild to Moderate Alzheimer Disease
}

\author{
D. P. Devanand, MD; Diane M. Jacobs, PhD; Ming-Xin Tang, PhD; Caridad Del Castillo-Castaneda; \\ Mary Sano, PhD; Karen Marder, MD; Karen Bell, MD; Frederick W. Bylsma, PhD; \\ Jason Brandt, PhD; Marilyn Albert, PhD; Yaakov Stern, PhD
}

\begin{abstract}
Background: The onset and course of the psychopathologic features of Alzheimer disease have not been established in prospective, longitudinal studies.

Methods: Two hundred thirty-five patients with early, probable Alzheimer disease were recruited at 3 sites and observed naturalistically for up to 5 years. At 6-month intervals, the Columbia University Scale for Psychopathology in Alzheimer's Disease was administered. Markov analyses were used to predict the probability of a specific symptom developing or being maintained at the next visit. For each symptom category, the maximum frequency of occurrence at 4 consecutive points (duration, 2 years) was calculated.
\end{abstract}

Resulis: Misidentification, wandering or agitation, and physical aggression increased during follow-up. At any visit, the likelihood of a new symptom developing was greatest for behavioral disturbance, intermediate for paranoid delusions and hallucinations, and least for depressed mood with vegetative features. Wandering or agitation occurred at 3 or more of 4 consecutive visits (duration, 2 years) in the majority of patients, paranoid delusions and hallucinations were intermediate in their degree of persistence, and depressed mood with vegetative signs rarely persisted.

Conelusions: Behavioral disturbance, particularly agitation, is common and persistent in patients with Alzheimer disease. Psychotic symptoms are less common and show moderate persistence over time. Depressed mood with vegetative signs is uncommon and rarely persists. These findings suggest leads about the optimal treatment duration for specific subtypes of psychopathologic features.

Arch Gen Psychiatry. 1997;54:257-263
From the Memory Disorders Clinic in the New York State Psychiatric Institute, the Center for Alzheimer's Disease Research in New York City, and the Departments of Psychiatry (Drs Devanand and Stern) and Neurology (Drs Jacobs, Tang, Sano, Marder, Bell, and Stern and Ms Del Castillo-Castaneda) and the Gertrude $H$. Sergievsky Center (Drs Jacobs, Tang, Sano, Marder, Bell, Stern, and Ms Del Castillo-Castaneda), College of Physicians and Surgeons of Columbia University, New York, NY; the Department of Psychiatry and Behavioral Sciences, The Johns Hopkins University, Baltimore, $\mathrm{Md}$ (Drs Bylsma and Brandt); and the Departments of Psychiatry and Neurology, Massachusetts General Hospital, Harvard Medical School, Boston (Dr Albert).

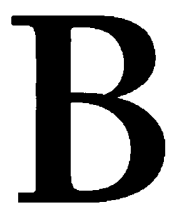

EHAVIORAL complications that are distressing to patients and caregivers, that are often treated with psychotropic medications, and that may increase the risk of institutionalization commonly develop in patients with Alzheimer disease (AD).$^{1-4}$ Agitation may occur in up to half of the patients with $\mathrm{AD}$ in outpatient clinics ${ }^{5,6}$ and nursing homes 7,8 ; physical aggression is less common. ${ }^{6,9,10}$ Common delusions in patients with AD include the belief that people are stealing their possessions and misidentification (eg, one's living place is not one's home). ${ }^{1}$ The prevalence of delusions, which are more often isolated symptoms than diagnosable psychotic disorders, ranges from $0 \%$ to $50 \%$ in different samples. ${ }^{11-16}$ The prevalence of psychosis and behavioral disturbance increases with disease progression and may herald a poor prognosis., ${ }^{214,17-19}$ Hallucinations, more often visual than auditory, rarely manifest early in the illness but may be more common in severe demen- tia. ${ }^{14,16,20,21}$ Approximately $10 \%$ to $30 \%$ of the patients with $A D$ meet the diagnostic criteria for major depression, but it remains unclear if depression is characteristic of any stage of the illness. ${ }^{22-26}$

The symptoms of AD are known to fluctuate over time. ${ }^{2,5,13,14}$ However, the onset and course of these symptoms have not been established in prospective, longitudinal studies. ${ }^{27,28}$ This lack of knowledge about the likely "episode duration" of specific symptoms has led to uncertainties about the prediction of the clinical course and the optimal duration of treatment. The latter is important because psychotropic medication use is associated with increased side effects in the elderly (eg, neuroleptic-induced extrapyramidal signs and tardive dyskinesia). ${ }^{29,30}$

We reported single-site, crosssectional data on the development and use of the Columbia University Scale for Psychopathology in Alzheimer's Disease (CUSPAD), a short semistructured instrument that can be administered by clinicians or trained research technicians..$^{16}$ As 


\section{SUBJECTS AND METHODS}

\section{SUBJECTS}

A cohort of patients with early, probable AD was recruited at 3 sites: Columbia University (CU), New York, NY; The Johns Hopkins University School of Medicine (JHU), Baltimore, Md; and Massachusetts General Hospital (MGH), Boston. Informed consent was obtained from the patient and an informant (ie, a family member, close friend, or health aide) who also served as a patient advocate. No intersite differences were noted for most demographic and clinical features, including sex, ethnicity, educational level, and severity of dementia. ${ }^{31}$ Patients at MGH were older (age, $77.5 \pm 9.5$ years) compared with those at $\mathrm{CU}$ (age, $71.0 \pm 8.0$ years) and JHU (age, $72.3 \pm 7.8$ years); ages are given as the mean $\pm S D$.

Detailed neurologic, psychiatric, and neuropsychological examinations were conducted initially and at 6-month intervals. Baseline laboratory tests included relevant blood studies, a computed tomographic or magnetic resonance imaging scan of the brain, and electroencephalogram and cerebrospinal fluid studies, if indicated. Patients met DSM-III-R criteria for primary degenerative dementia of the Alzheimer type ${ }^{32}$ and National Institute of Neurological Disorders and Stroke-Alzheimer's Disease and Related Disorders Association criteria for probable AD. ${ }^{33}$ Entry criteria required an expanded modified Mini-Mental State Examination (mMMSE) score of 30 or more of 57 (approximately equivalent to $\geq 16$ on the original MiniMental State Examination). ${ }^{34,35}$

Exclusion criteria were a history of schizophrenia or schizoaffective disorder, electroconvulsive therapy within the preceding 2 years or a history of 10 or more electroconvulsive therapy treatments in any one course, alcohol or drug dependence during the preceding 5 years, primary affective disorder within 1 year before the onset of dementia, and evidence of other causes of dementia. Patients with a history or clinical signs of stroke, radiological evidence of cortical lesions or focal cortical atrophy secondary to an infarct, or other vascular lesions $2 \mathrm{~cm}$ or more in diameter in any 1 computed tomographic or magnetic resonance imaging slice were excluded. ${ }^{31}$

Patients receiving thyroid replacement therapy (ie, $3.4 \%$ ) were euthyroid. At the initial examination, $9 \%$ of the patients were participating in placebo-controlled research drug trials, including trials for oral physostigmine, piracetam, acetyl-t-carnitine, selegiline hydrochloride, and tetrahydroaminoacridine. A similar proportion of patients participated in these trials during follow-up.

\section{COLUMBIA UNIVERSITY SCALE FOR PSYCHOPATHOLOGY IN ALZHEIMER'S DISEASE}

A trained research technician administered the CUSPAD to the informant at the initial examination and at 6-month intervals. The frame of inquiry was the month before examination. Most CUSPAD items are scored dichotomously (ie, present or absent).

The 5 items for behavioral disturbance were wandering, agitation (ie, restlessness or increased motor activity), verbal outbursts, physical aggression (including threatening behavior), and sundowning (ie, increased agitation in the evening compared with the daytime). The items for depression were depressed mood, difficulty sleeping (ie, insomnia or hypersomnia), and change in appetite (ie, decreased or increased).

For delusions, the categories were any type (overall category), paranoid (including the belief that people were stealing things), misidentification (including the belief that the patient's house was not his or her home), somatic, and abandonment. For each delusion, the broad definition was met when the patient did not accept the caregiver's correction of the false belief, while a narrow definition was met when the patient did not accept the caregiver's correction of the false belief and the symptom occurred more than 3 times per week. Hallucinations were rated as vague or clear in each of 4 sensory modalities (ie, auditory, visual, tactile, and olfactory).

The analyses used the broad definition of a delusion and the presence of either a vague or clear hallucination (any sensory modality) for the following reasons. First, many clinicians can identify whether a broadly defined delusion or hallucination is present. Second, if a patient switches from meeting narrow to broad criteria for a delusion, use of the narrow definition results in the patient being misclassified as switching from delusional to nondelusional (ie, a type II error). Similarly, a restriction to only clear hallucinations is problematic if patients switch from clear to vague (or vice versa) during follow-up.

\section{ANALYSIS PLAN}

The presence of any 1 symptom within a category led to a positive score for that category. The following symptom categories were evaluated as dichotomous variables (ie, present or absent): delusions (any type), paranoid, misidentification, somatic, and abandonment delusions, hallucinations (any type), behavioral disturbance, insomnia, and depressed mood. Analyses were also conducted for specific symptoms of a priori interest, ie, wandering or agitation (a positive score for either item), physical aggression, and depressed mood with vegetative signs (ie, sleep and appetite disturbance).

Markov analyses were conducted to evaluate the course of the psychopathologic features. In this model, the current symptom status and relevant risk factors were used to predict the probability of transition to specified outcomes (ie, developing or maintaining the symptom) at the next visit (after the 6-month interval). Separately, to assess the persistence of symptoms during follow-up, the maximum frequency of occurrence of each symptom category at any 4 consecutive points (duration, 2 years), regardless of when it was first manifested, was calculated.

The main descriptive and related analyses were restricted to the first 3 years of follow-up because the number of subjects decreased further with longer followup. For the Markov analyses and evaluation of the persistence of symptoms, all available points (maximum, 5 years of follow-up) were used. Given the large sample size, a conservative $P<.01$ was used as the threshold criterion for significance in all analyses. All data are given as the mean $\pm S D$. 
Table 1. Prevalence (Percentage) of Psychopathologic Features at 6-Month Intervals During 3 Years of Follow-up

\begin{tabular}{|c|c|c|c|c|c|c|c|c|}
\hline \multirow[b]{2}{*}{$\begin{array}{l}\text { Psychopathologic } \\
\text { Feature }\end{array}$} & \multicolumn{7}{|c|}{ Time, y } & \multirow{2}{*}{$\begin{array}{c}\text { Test of } \\
\text { Linearity } \\
P\end{array}$} \\
\hline & $\begin{array}{c}\text { Intake } \\
(n=235)\end{array}$ & $\begin{array}{c}0.5 \\
(n=198)\end{array}$ & $\begin{array}{c}1.0 \\
(n=188)\end{array}$ & $\begin{array}{c}1.5 \\
(n=177)\end{array}$ & $\begin{array}{c}2.0 \\
(n=157)\end{array}$ & $\begin{array}{c}2.5 \\
(n=156)\end{array}$ & $\begin{array}{c}3.0 \\
(n=137)\end{array}$ & \\
\hline Any type of delusion & 23.9 & 27.8 & 31.9 & 32.8 & 33.1 & 35.3 & 31.4 & $<.05$ \\
\hline Paranoid & 14.5 & 21.7 & 19.1 & 18.6 & 14.6 & 17.9 & 18.2 & .94 \\
\hline Misidentification & 10.2 & 11.1 & 13.3 & 18.6 & 21.7 & 22.4 & 18.3 & $<.005$ \\
\hline Somatic & 1.3 & 0.5 & 2.7 & 2.8 & 2.5 & 4.5 & 2.2 & .06 \\
\hline Abandonment & 1.3 & 1.5 & 4.3 & 4.0 & 0.6 & 1.9 & 2.9 & .66 \\
\hline Hallucinations & 8.1 & 8.1 & 11.6 & 17.0 & 11.3 & 19.8 & 12.2 & .31 \\
\hline Behavior disturbance & 51.9 & 51.5 & 62.2 & 61.0 & 66.9 & 71.2 & 65.7 & $<.001$ \\
\hline Wandering or agitation & 38.7 & 39.9 & 47.3 & 50.9 & 52.2 & 62.2 & 56.9 & $<.001$ \\
\hline Physical aggression & 6.4 & 8.6 & 9.6 & 11.3 & 19.8 & 20.5 & 19.0 & $<.001$ \\
\hline Depressed mood & 25.1 & 20.2 & 26.6 & 23.3 & 21.7 & 19.9 & 22.6 & .65 \\
\hline Insomnia & 13.6 & 9.7 & 8.9 & 14.6 & 9.3 & 13.3 & 11.3 & .73 \\
\hline Depressed mood with & & & & & & & & \\
\hline vegetative signs & 6.8 & 7.1 & 6.4 & 6.8 & 8.3 & 7.7 & 4.4 & .89 \\
\hline
\end{tabular}

part of a prospective, longitudinal, multicenter study, the CUSPAD was used to evaluate the course of the psychopathologic features in patients recruited at the stage of early, probable AD. ${ }^{31}$

\section{RESUITS}

\section{DEMOGRAPHIC AND CLINICAL FEATURES}

Of the 235 patients, 94 were from CU, 80 were from JHU, and 61 were from MGH. The number of patients decreased during the study period (Toble 1 ). During the first 3 years, reasons for unavailability for follow-up included death $(n=53)$, severe medical illness $(n=9)$, change of residence $(n=13)$, and other causes, including refusal $(n=23)$.

At the initial examination, the age of the patients was $73.1 \pm 8.9$ years; $82.1 \%$ were aged 65 years or older. The duration of the illness was $4.0 \pm 2.6$ years, and the educational attainment of the patients was $13.1 \pm 3.7$ years. Most patients were women (ie, 59.1\%); the ethnic breakdown of the patients was $89.8 \%$ non-Latino white, $3.4 \%$ Latino, 6.4\% African American, and 0.4\% other (ie, 1 patient of African American, Irish, and Native American origin). At the initial examination, $91.1 \%$ lived at home, $6.8 \%$ lived in a nursing home, $1.3 \%$ lived in a retirement home, and $0.9 \%$ had other living situations. At the 3-year followup, $26.8 \%$ resided in a nursing home.

The duration of follow-up was $3.0 \pm 2.5$ years. The mMMSE score (maximum score, 57 ) decreased from $37.9 \pm 5.6$ at the initial examination to $32.2 \pm 9.8$ at $l$ year, $27.2 \pm 12.7$ at 2 years, and $20.6 \pm 15.0$ at 3 years (test of linearity: $F=429.8, P<.001$ ). The Blessed Functional Activity Scale (BFAS) score (from $0=$ no impairment to $17=$ severe impairment $)^{36,37}$ increased from $3.5 \pm 1.9$ at the initial examination to $5.0 \pm 2.6$ at 1 year, $6.6 \pm 3.6$ at 2 years, and $8.2 \pm 4.3$ at 3 years (test of linearity: $F=476.6$, $P<.001$ ). These changes are consistent with prior reports ${ }^{17,36}$ about the rate of cognitive and functional decline in mild to moderate AD.

At the initial examination, most informants reported frequent contact with the patient (contact dur- ing the previous year, $287.7 \pm 124.8$ days), and $63.6 \%$ of them lived with the patient. The bulk of informants comprised spouses (ie, 56.9\%) and adult children (ie, 31.9\%). The informant rarely changed during follow-up: spouses, $57.4 \%$ at 1 year, $60.0 \%$ at 2 years, and $61.0 \%$ at 3 years; adult children, $31.7 \%$ at 1 year, $31.5 \%$ at 2 years, and $31.5 \%$ at 3 years.

A history of a psychiatric disorder (any type) before the onset of $A D$ was reported in $19.9 \%$ of the patients, among whom $70 \%$ had a history of depression (subtype unspecified). Antidepressant use did not change notably during follow-up: $9.4 \%$ at the initial examination, $12.6 \%$ at 1 year, $9.6 \%$ at 2 years, and $14.3 \%$ at 3 years. Neuroleptic use increased during follow-up: $0.4 \%$ at the initial examination, $6.3 \%$ at 1 year, $16.6 \%$ at 2 years, and $18.5 \%$ at 3 years. Sedative or hypnotic use also increased during follow-up: $5.5 \%$ at the initial examination, $5.2 \%$ at 1 year, $7.6 \%$ at 2 years, and $16.0 \%$ at 3 years. Overall, the proportion of patients receiving psychotropic medications (any type) increased during followup: $14.0 \%$ at the initial examination, $20.9 \%$ at 1 year, $27.4 \%$ at 2 years, and $38.7 \%$ at 3 years.

\section{RELIABILITY, DIVERGENT VALIDITY, AND INTERSITE COMPARISONS}

We have reported interrater reliability for the major symptom categories between the principal scale developer (D.P.D.) and a research technician (trained by D.P.D.), whether concurrently rating a single interview $(\kappa=0.74-1.00)$ or conducting separate interviews $(\kappa=0.53-0.73) .{ }^{16}$ These 2 raters trained the research technicians at the other sites and provided ongoing consultation when patients were difficult to rate.

At the initial examination, moderate associations were noted among paranoid delusions, misidentification delusions, and behavioral disturbance $\left(\chi^{2}, 10.6-\right.$ $12.0 ; d f=1 ; P<.01)$. These 3 symptom categories showed no notable associations with either hallucinations or depressed mood, extending the strong divergent validity previously reported from the $\mathrm{CU}$ site alone. ${ }^{16}$

At the initial examination, no intersite differences 


\begin{tabular}{|c|c|c|c|c|c|c|c|c|c|}
\hline \multirow[b]{2}{*}{ Symptom } & \multirow[b]{2}{*}{ Prevalence } & \multicolumn{2}{|c|}{ mMMSE } & \multirow[b]{2}{*}{$t$} & \multirow[b]{2}{*}{$P<$} & \multicolumn{2}{|c|}{ BFAS } & \multirow[b]{2}{*}{$t$} & \multirow[b]{2}{*}{$P<$} \\
\hline & & Mean & SD & & & Mean & SD & & \\
\hline \multirow[t]{2}{*}{ Any type of delusion } & Present & 36.4 & $4.5-$ & \multirow{2}{*}{2.3} & \multirow{2}{*}{.02} & 4.1 & 1.77 & \multirow{2}{*}{2.6} & \multirow{2}{*}{.01} \\
\hline & Absent & 38.4 & $5.8-$ & & & 3.4 & $1.9\rfloor$ & & \\
\hline \multirow[t]{2}{*}{ Paranoid } & Present & 38.1 & $5.7-$ & \multirow{2}{*}{1.4} & \multirow{2}{*}{.20} & 3.9 & 1.77 & \multirow{2}{*}{1.1} & \multirow{2}{*}{.30} \\
\hline & Absent & 36.6 & 4.7 & & & 3.5 & $1.9\rfloor$ & & \\
\hline \multirow[t]{2}{*}{ Misidentification } & Present & 35.4 & $3.8-$ & \multirow{2}{*}{3.2} & \multirow{2}{*}{.01} & 4.6 & 1.87 & \multirow[b]{2}{*}{2.6} & \multirow[b]{2}{*}{.01} \\
\hline & Absent & 38.2 & $5.7\rfloor$ & & & 3.4 & $1.9]$ & & \\
\hline \multirow{2}{*}{ Hallucinations } & Present & 35.9 & 5.17 & \multirow[b]{2}{*}{1.6} & \multirow[b]{2}{*}{.20} & 3.7 & 1.57 & \multirow{2}{*}{0.4} & \multirow[b]{2}{*}{.70} \\
\hline & Absent & 38.0 & $5.6]$ & & & 3.5 & $1.9]$ & & \\
\hline \multirow[t]{2}{*}{ Behavior disturbance } & Present & 37.0 & 4.77 & \multirow{2}{*}{2.6} & \multirow{2}{*}{.01} & 3.8 & 1.97 & \multirow{2}{*}{2.0} & \multirow{2}{*}{.05} \\
\hline & Absent & 38.8 & $6.3\rfloor$ & & & 3.3 & $1.8]$ & & \\
\hline Wandering or agitation & Present & 36.9 & 4.97 & & & 3.9 & 2.17 & & \\
\hline & Absent & 38.5 & $5.9]$ & 2.2 & .05 & 3.3 & $1.7\rfloor$ & 2.4 & .02 \\
\hline Physical aggression & Present & 36.8 & 4.47 & & & 4.5 & 1.97 & & \\
\hline & Absent & 37.9 & $5.6]$ & 0.8 & .40 & 3.5 & $1.9]$ & 2.0 & .05 \\
\hline Depressed mood & Present & 36.0 & 4.87 & & & 3.9 & 1.87 & & \\
\hline & Absent & 38.5 & $5.7\rfloor$ & 3.0 & .01 & 3.4 & $1.9\rfloor$ & 1.6 & .20 \\
\hline Insomnia & Present & 36.7 & 5.77 & & & 4.5 & & & \\
\hline & Absent & 37.9 & $5.6]$ & 1.0 & .30 & 3.4 & $1.8]$ & 3.0 & .01 \\
\hline Depressed mood with & Present & 35.1 & 5.17 & 21 & 05 & 4.6 & 2.67 & 24 & $0 ?$ \\
\hline vegetative signs & Absent & 38.1 & $5.6]$ & 2.1 & .05 & 3.5 & $1.8]$ & 2.4 & .02 \\
\hline
\end{tabular}

*mMMSE indicates modified Mini-Mental State Examination; BFAS, Blessed Functional Activity Scale, part 1; and $\mathrm{t}$, 2-tailed Student $\mathrm{t}$ test.

for the prevalence of psychotic and depressive features were noted. Behavioral disturbance differed in prevalence at the 3 sites (CU, $62.8 \%$; JHU, $52.5 \%$; and $M G H$, $34.4 \%)\left(\chi^{2}=11.9, P<.005\right)$, primarily because of differences in the prevalence of agitation or wandering (CU, $51.1 \%$; JHU, 36.3\%; and MGH, 23\%) $\left(\chi^{2}=12.6, P<.005\right)$.

\section{PREVALENCE OF SYMPTOMS}

At the initial examination, $64.3 \%$ of the patients had 1 or more psychopathologic symptom. During the first 3 years of follow-up, only $8.5 \%$ of the patients remained free of all symptoms of psychosis, behavioral disturbance, and depression. Misidentification delusions and behavioral disturbance were the only symptom categories that significantly increased during follow-up. Wandering or agitation and physical aggression contributed to the increase in behavioral disturbance (Table 1). Similar results were obtained when the sample was restricted to the 156 patients who completed 3 years of follow-up. Somatic and abandonment delusions were rare at all points and were not analyzed further.

\section{RELATION OF SYMPTOM CATEGORIES TO CLINICAL VARIABLES AT THE INITIAL EXAMINATION}

At the initial examination, sex, ethnicity, age, duration of illness, years of education, and history of psychiatric disorder were not associated with the presence of any symptom category. Greater cognitive impairment (ie, low mMMSE score) occurred in patients with misidentification delusions, behavioral disturbance, and depressed mood. Increased functional impairment (ie, a high BFAS score) occurred in patients with delusions (any type), misidentification delusions, and insomnia. Associations be- tween the other symptom categories, mMMSE scores, and BFAS scores were either at the trend level or not significant (Table 2).

\section{MARKOV ANALYSES}

Markov analyses were conducted to evaluate the transition probabilities for the onset (ie, absent at 1 point but present at the next point) and persistence (ie, present at 1 point and at the next) of specific symptoms (Table 3 ). For the onset of new symptoms, the transition probability was greatest for behavioral disturbance (ie, .36, which means that $36 \%$ of the patients without a behavioral disturbance at 1 visit manifested a behavioral disturbance at the next visit) and its subcategory of wandering or agitation and lowest for depressed mood with vegetative signs and insomnia. Hallucinations and paranoid and misidentification delusions showed intermediate transition probabilities. For persistence of symptoms, behavioral disturbance had the highest and depressed mood with vegetative signs had the lowest transition probability. The results of the Markov analyses were similar at each of the 3 sites.

Psychiatric history (covariate, present or absent) did not significantly alter the transition probabilities for any symptom category. A history of depression showed trendlevel associations for current depressed mood (Wald test, $P<.05)$. Neuroleptic use did not significantly decrease the transition probability for persistence of psychotic or behavioral symptoms, antidepressant use did not decrease the transition probability for persistence of depressed mood, and benzodiazepine use did not decrease the transition probability for persistence of behavioral disturbance or insomnia. The main Markov analyses were performed again after restricting the sample to patients who did not receive psychotropic medications at any time 


\begin{tabular}{|c|c|c|}
\hline \multirow[b]{2}{*}{$\begin{array}{l}\text { Psychopathologic } \\
\text { Feature }\end{array}$} & \multicolumn{2}{|c|}{$\begin{array}{l}\text { Transition Probabilities* } \\
(\mathrm{n}=1181) \dagger\end{array}$} \\
\hline & $\begin{array}{l}\text { Onset of New } \\
\text { Symptom }\end{array}$ & $\begin{array}{l}\text { Persistence } \\
\text { of Symptom }\end{array}$ \\
\hline Any type of delusionf & .17 & .59 \\
\hline Paranoid & .11 & .45 \\
\hline Misidentification & .10 & .56 \\
\hline Hallucinations & .09 & .52 \\
\hline Behavior disturbance & .36 & .80 \\
\hline Wandering or agitation & .31 & .74 \\
\hline Physical aggression & .10 & .53 \\
\hline Depressed mood & .14 & .47 \\
\hline Insomnia & .06 & .41 \\
\hline $\begin{array}{l}\text { Depressed mood with } \\
\text { vegetative signs }\end{array}$ & .05 & .28 \\
\hline
\end{tabular}

* Transition probabilities range from 0 to 1 . A transition probability of .11 for the onset of paranoid delusions indicates that $11 \%$ of the patients without a paranoid delusion manifested a paranoid delusion at the next visit (after the 6-month interval). A transition probability of .45 for the persistence of paranoid delusions indicates that $45 \%$ of the patients with a paranoid delusion again manifested a paranoid delusion at the next visit (after the 6-month interval).

tn indicates the number of subjects times the number of points at which the symptom was assessed.

$\ddagger n=1180$.

point, and similar results were obtained. The use of experimental drugs to enhance cognition in $\mathrm{AD}$ (covariate, present or absent) did not significantly alter the transition probability for any symptom category.

The presence of delusions, hallucinations, behavioral disturbance, or depressed mood at the initial examination was unassociated with an increased risk of dropout 6 months later. Similarly, the presence of these symptom categories at 12 months did not affect dropout at 18 months.

Additional Markov analyses for the onset of new symptoms were conducted with mMMSE (dichotomized around the mean of 38 , mild impairment) and BFAS (dichotomized around the median of 5) scores included as covariates. Patients with low mMMSE scores had a higher transition probability (ie, . 20 or $20 \%$ ) for the development of delusions (any type) at the next visit than patients with high mMMSE scores (transition probability, . 12 or $12 \%$; Wald test, $P<.01$ ). Patients with low mMMSE scores had a higher transition probability for the development of misidentification delusions (low vs high mMMSE score, .10 vs .04 ; Wald test, $P<.01$ ) and hallucinations (low vs high mMMSE score, .23 vs .03 ; $\mathrm{P}<.005$ ) but not paranoid delusions (low vs high mMMSE score, .13 vs . 10). Blessed Functional Activity Scale scores did not affect the transition probability for the development of any psychotic symptom. Patients with low mMMSE scores had a higher transition probability of behavioral disturbance developing (low vs high mMMSE score, .69 vs $.27 ; P<.001$ ), including the subcategories of wandering or agitation (low vs high mMMSE score, .57 vs $.20 ; P<.005$ ) and physical aggression (low vs high mMMSE score, .19 vs .03; $P<.001)$. High BFAS scores
Table 4. Persistence of Symptoms in Patients With Alzheimer Disease at 6-Month Intervals (5-Year Follow-up)

\begin{tabular}{lrrrrr|}
\hline \multirow{2}{*}{$\begin{array}{l}\text { Psychopathologic } \\
\text { Feature }\end{array}$} & Absent & $\mathbf{1}$ of $\mathbf{4}$ & $\mathbf{2}$ of $\mathbf{4}$ & $\mathbf{3}$ of $\mathbf{4}$ & $\mathbf{4}$ of $\mathbf{4}$ \\
\hline Any delusion & 30.6 & 20.0 & 17.8 & 18.9 & 12.8 \\
$\quad$ Paranoid & 46.1 & 23.9 & 13.9 & 12.2 & 3.9 \\
$\quad$ Misidentification & 54.4 & 17.2 & 14.4 & 8.3 & 5.6 \\
Hallucinations & 60.0 & 18.9 & 11.1 & 4.4 & 5.6 \\
Behavior disturbance & 8.3 & 9.4 & 14.4 & 21.7 & 46.1 \\
$\quad$ Wandering or agitation & 14.4 & 14.4 & 16.7 & 21.7 & 32.8 \\
$\quad$ Physical aggression & 61.1 & 14.4 & 12.8 & 8.9 & 2.8 \\
Depressed mood & 41.1 & 23.9 & 17.2 & 9.4 & 8.3 \\
$\quad$ Insomnia & 64.4 & 17.2 & 10.6 & 5.6 & 1.7 \\
$\quad$ Depressed mood with & & & & & \\
$\quad$ vegetative signs & 71.7 & 19.4 & 7.8 & 0.0 & 1.1 \\
\end{tabular}

* Maximum frequency for the presence of each symptom category at any 4 consecutive points, regardless of when the symptom was first manifested. All values are percentages.

increased the transition probability of physical aggression only developing (high vs low BFAS score, .07 vs .03; $P<.01)$. Neither mMMSE nor BFAS scores affected the likelihood of developing depressed mood or depressed mood with vegetative features.

\section{PERSISTENCE OF SYMPTOMS AT 6-MONTH INTERVALS DURING FOLLOW-UP}

The persistence of specific symptoms was evaluated by using all available follow-up points (up to 5 years). The maximum frequency of symptoms at any 4 consecutive visits, regardless of when the symptom was first manifested, was calculated. A total of 180 patients completed a minimum of 4 consecutive visits (duration, 2 years).

Paranoid delusions, hallucinations, and misidentification delusions usually did not persist for 4 consecutive visits (Table 4). However, misidentification delusions doubled in frequency during the first 3 years of follow-up (Table 2), and even longer follow-up may have revealed greater persistence of this symptom. Behavioral disturbance was the most persistent symptom category, with wandering or agitation largely accounting for this effect. Wandering or agitation was present at 3 or more of 4 consecutive visits in the majority (ie, 54.5\%) of the sample, but physical aggression rarely persisted (ie, $2.8 \%$ at 4 consecutive visits). Depressed mood was present at 4 consecutive visits in $8.3 \%$ of the sample, and depressed mood with vegetative signs was the least persistent $(1.1 \%$ at $\geq 3$ of 4 visits) of all the symptoms examined (Table 4).

During these 4 consecutive visits with maximum symptom frequency, neuroleptic use was associated with paranoid delusions $\left(\chi^{2}=17.5, d f=4, P<.002\right)$, misidentification delusions $\left(\chi^{2}=21.0, d f=4, P<.001\right)$, hallucinations $\left(\chi^{2}=20.5, d f=4, P<.001\right)$, and behavioral disturbance $\left(\chi^{2}=26.7, d f=4, P<.001\right)$. Antidepressant use tended to be associated with depressed $\operatorname{mood}\left(\chi^{2}=11.1, d f=4\right.$, $P<.05)$. Benzodiazepine use tended to be associated with the presence of behavioral disturbance $\left(\chi^{2}=12.2, d f=4\right.$, 
$P<.02$ ) but not with insomnia (a low-frequency symptom), depressed mood, or any psychotic feature.

\section{COMMENT}

In this multicenter, prospective study, the prevalence of specific types of psychopathologic features was consistent with findings from other studies of outpatients with AD ${ }^{5,13,15,21,38-41}$ Behavioral disturbance, particularly wandering or agitation, occurred in half the sample. Paranoid and misidentification delusions and hallucinations were less common. Somatic and abandonment delusions were rare. ${ }^{14}$ Depressed mood occurred in one quarter of the sample, but depressed mood with vegetative signs was rare.

The prospective, longitudinal data are novel and have implications for clinicians and caregivers. Behavioral disturbance was common and often persistent, primarily because of the symptom of agitation. ${ }^{42}$ Physical aggression was infrequent and persisted for 2 years or more in only $2.8 \%$ of the sample. However, Markov analyses indicated a 53\% probability for physical aggression to persist from one visit to the next, and this symptom tripled in frequency from the initial examination to the 3-year follow-up examination. Therefore, physical aggression may show greater persistence in more advanced stages than those evaluated in this study. ${ }^{2,9}$ Misidentification delusions doubled in frequency during follow-up, suggesting that this symptom may become more persistent in advanced stages. Paranoid delusions and hallucinations did not increase notably during the study period. These symptoms showed moderate persistence from one visit to the next and rarely persisted for 4 consecutive visits. 15,21

The prevalence of depressed mood did not change during the study. Depressed mood with vegetative signs was uncommon at all points and rarely persisted. However, prior studies indicate that $10 \%$ to $30 \%$ of patients with $A D$ meet the diagnostic criteria for major depression. ${ }^{14,22}$ Nonspecific symptoms in patients with AD (eg, psychomotor change, apathy or lack of interest, sleep difficulties, and poor concentration) may artificially raise prevalence rates for major depression. ${ }^{26,43,44}$ Three methodological caveats should be noted: patients with early $A D$ who often manifest depression may have been missed because of the entry criteria, ${ }^{45}$ antidepressant treatment may have altered symptom presentation in this naturalistic study, and the informant's mood state is known to influence reporting of depression in the patient with $\mathrm{AD}{ }^{46}$

During follow-up, strong associations existed between specific subtypes of target psychopathologic feature and the use of psychotropic medications. However, Markov analyses also indicated that these medications did not notably decrease the likelihood of symptom persistence. These data about psychotropic medications have limitations. Treatment was based on the physician's choice, and optimal dosing and patient compliance were not ensured. The CUSPAD was developed primarily to study phenomenological featues and not to assess change in treatment trials, and most items lack quantitative ratings of severity. Therefore, medication-induced reduc- tions in symptom severity, without symptom remission, would have been missed with this instrument. ${ }^{16}$

Nevertheless, the persistent nature of agitation indirectly suggests that treatment of this target behavior may need to be prolonged. Paranoid delusions and hallucinations were somewhat less persistent, indicating that not all patients need long-term neuroleptic treatment for these symptoms. The evanescent nature of depressed mood with vegetative features suggests that short-term treatment strategies may be appropriate. ${ }^{47}$ These speculations need to be tested by empirical research.

The baseline data and the longitudinal analyses indicated that most psychotic features and behavioral disturbances were associated with greater cognitive impairment, except for paranoid delusions. ${ }^{48,49}$ Functional impairment did not show notable associations with measures of psychosis in the longitudinal data set, but high BFAS scores did increase the likelihood of the onset of physical aggression. The lack of association between depressive symptoms and either cognitive or functional impairment suggests that depression may not be characteristic of any specific stage in patients with mild to moderate AD. ${ }^{14}$

In summary, this prospective, longitudinal study of a multicenter cohort of outpatients with $\mathrm{AD}$ provided new information about the likely duration and persistence of psychopathologic symptoms. Behavioral disturbance, particularly agitation, is common and persistent in patients with AD. Psychotic symptoms are less common and show moderate persistence over time. Depressed mood with vegetative signs is uncommon and rarely persists. These naturalistic data suggest leads about the optimal treatment duration for specific subtypes of psychopathologic features, an issue that needs to be tested by empirical research.

\section{Accepted for publication April 22, 1996.}

This work was supported in part by federal grants AG07370, AG08702, and RR00645 from the National Institute on Aging and MH44176 and MH50038 from the National Institute of Mental Health, Bethesda, Md; and the Charles S. Robertson Memorial Gift for Alzheimer Disease Research.

Reprints: Yaakov Stern, PhD, Sergievsky Center, 19th Floor, $630 \mathrm{~W}$ 168th St, New York, NY 10032.

\section{REFERENCES}

1. Reisberg B, Borenstein J, Salob SP, Ferris SH, Franssen E, Georgotas A. Behavioral symptoms in Alzheimer's disease: phenomenology and treatment. $J$ Clin Psychiatry. 1987;48:9-15.

2. Rubin $E$, Drevets $W$, Burke WJ. The nature of psychotic symptoms in senile dementia of the Alzheimer type. J Geriatr Psychiatry Neurol. 1988;1:16-20.

3. Devanand D, Sackeim H, Brown R, Mayeux R. A pilot study of haloperidol treatment of psychosis and behavioral disturbance in Alzheimer's disease. Arch Neurol. 1989:46:854-857.

4. Schneider LS, Pollock VE, Lyness SA. A meta-analysis of controlled trials of neuroleptic treatment in dementia. J Am Geriatr Soc. 1990;38:553-563.

5. Teri L, Larson EB, Reifler BV. Behavioral disturbance in dementia of the Alzheimer's type. J Am Geriatr Soc. 1988;36:1-6.

6. Devanand DP, Brockington CD, Moody BJ, Brown RP, Mayeux R, Endicott J, Sackeim HA. Behavioral syndromes in Alzheimer's disease. Int Psychogeriatr. 1992;4:161-184.

7. Chandler JD, Chandler JE. The prevalence of neuropsychiatric disorders in a 
nursing home population. J Geriatr Psychiatry Neurol. 1988;1:7†-76.

8. Cohen-Mansfield J, Marx MS, Rosenthal AS. A description of agitation in a nursing home. Gerontology. 1989;3:M77-M84.

9. Swearer JM, Drachman DA, O'Donnell BF, Mitchell AL. Troublesome and disruptive behaviors in dementia. J Am Geriatr Soc. 1988;36:784-790.

10. Haller $E$, Binder RL, McNeil DE. Violence in geriatric patients with dementia. Bull Am Acad Psychiatry Law. 1989;17:183-188.

11. Bucht $G$, Adolfsson R. The comprehensive psychopathological rating scale in patients with dementia of Alzheimer type and multi-infarct dementia. Acta Psychiatr Scand. 1983;68:263-270.

12. Mayeux R, Stern Y, Sano M. Psychosis in patients with dementia of the Alzheimer type. Ann Neurol. 1985;18:184-187.

13. Reisberg B, Franssen E, Sclan SG, Kluger A, Ferris SH. Stage-specific incidence of potentialiy remediable behavioral symptoms in aging and Alzheimer's disease: a study of 120 patients using the BEHAVE-AD. Bull Clin Neurosci. 1989;54:95-112.

14. Wragg RE, Jeste DV. Overview of depression and psychosis in Alzheimer's disease. Am J Psychiatry. 1989;146:577-587.

15. Burns A, Jacoby R, Levy R. Psychiatric phenomena in Alzheimer's disease, I: disorders of thought content. Br J Psychiatry. 1990;157:72-76.

16. Devanand DP, Miller L, Richards M, Marder K, Bell K, Mayeux R, Stern Y. The Columbia University Scale for Psychopathology in Alzheimer's Disease. Arch Neurol. 1992;49:371-376.

17. Stern $Y$, Mayeux R, Sano M, Hauser WA, Bush T. Predictors of disease course in patients with probable Alzheimer's disease. Neurology. 1987;37:1649-1653.

18. Drevets WC, Rubin EH. Psychotic symptoms and the longitudinal course of dementia of the Aizheimer type. Biol Psychiatry. 1989;25:39-48.

19. Rosen J, Zubenko GS. Emergence of psychosis and depression in the longitudinal evaluation of Alzheimer's disease. Biol Psychiatry. 1991;29:224-232.

20. Haddad PM, Benbow SM. Visual hallucinations as the presenting symptom of senile dementia. Br J Psychiatry. 1992;161:263-265.

21. Burns A, Jacoby R, Lewy R. Psychiatric phenomena in Alzheimer's disease, II: disorders of perception. Br J Psychiatry. 1990;157:76-81.

22. Greenwald BS, Kramer-Ginsberg E, Marin DB, Laitman LB, Hermann CK, Mohs $\mathrm{RC}$, Davis Ki. Dementia with coexistent major depression. Am J Psychiatry. 1989;146:1472-1478.

23. Rovner BW, Broadhead J, Spencer M, Carson K, Folstein MF. Depression and Alzheimer's disease. Am J Psychiatry. 1989;146:350-353.

24. Reifler BV, Larson $E$, Hanley R. Coexistence of cognitive impairment and depression in geriatric outpatients. Am J Psychiatry. 1982;139:623-626.

25. Ballard CG, Cassidy G, Bannister C, Mohan RNC. Prevalence, symptom profile, and aetiology of depression in dementia sufferers. J Affect Disord. 1993;29: 1-6.

26. Forsell $Y$, Jorm AF, Fratiglioni $L$, Grut $M$, Winblad B. Application of DSM-III-R criteria for major depressive episode to elderly subjects with and without dementia. Am J Psychiatry. 1993;150:1199-1202.

27. Raskind M, Risse S, Lampe T. Dementia and antipsychotic drugs. J Clin Psychiatry. 1987;48:16-18.

28. Devanand DP. Role of neuroleptics in treatment of behavioral complications. In: Lawlor BA, ed. Behavioral Complications in Alzheimer's Disease. Washington, DC: American Psychiatric Press; 1995:131-151.

29. Casey DE. Neuroleptic drug-induced extrapyramidal syndromes and tardive dyskinesia. Schizophr Res. 1991:4:109-120.

30. Jeste DV, Lacro JP, Gilbert PL, KIIne J, Kline N. Treatment of late-life schizophrenia with neuroleptics. Schizophr Bull. 1993;19:817-830

31. Stern $Y$, Folstein M, Albert M, Richards M, Miller L, Bylsma F, Lafleche G, Marder K, Bell K, Sano M, Devanand DP, Loreck D, Wootten J, Bello J. Mul- ticenter study of predictors of disease course in Alzheimer disease (the 'predictors study'), l: study design, cohort description, and intersite comparisons. Alzheimer Dis Assoc Disord. 1993;7:3-21.

32. American Psychiatric Association. Diagnostic and Statistical Manual of Mental Disorders, Third Edition, Revised. Washington, DC: American Psychiatric Association; 1987.

33. McKhann G, Drachman D, Folstein M. Clinical diagnosis of Alzheimer's disease: report of the NINCDS-ADRDA Work Group under the auspices of Department of Health and Human Services Task Force on Alzheimer's Disease. Neurology. 1984;34:939-944.

34. Mayeux R, Stern Y, Rosen J, Leventhal J. Depression, intellectual impairment and Parkinson's disease. Neurology. 1981;31:645-650.

35. Folstein M, Folstein S, McHugh P. 'Mini-Mental State': a practical method of grading the cognitive state of patients for clinicians. J Psychiatr Res. 1975; 12:189-198

36. Blessed $G$, Tomlinson BE, Roth $M$. The association between quantitative measures of dementia and of senile change in the cerebral grey matter of elderly subjects. Br J Psychiatry. 1968:114:797-811.

37. Stern Y, Andrews H, Pittman J, Sano M, Tatemichi T, Lantigua R, Mayeux R. Diagnosis of dementia in a heterogeneous population: development of a neuropsychological paradigm-based diagnosis of dementia and quantified correction for the effects of education. Arch Neurol. 1992;49:453-460.

38. Rubin EH, Kinscherf DA, Morris JC. Psychopathology in younger versus older persons with very mild and mild dementia of the Alzheimer type. Am J Psychiatry. 1993;150:639-642.

39. Cohen D, Eisdorfer CG, Paveza G, Luchins DJ, Freels S, Ashford JW, Semal T, Levy P, Hirschman R. Psychopathology associated with Alzheimer's disease and related disorders. J Gerontol. 1993;48:M255-M260.

40. Tariot PN, Mack JL, Patterson MB, Edland SD, Weiner MF, Fillenbaum G, Blazina L, Teri L, Rubin E, Mortimer JA, Stern Y. The Behavior Rating Scale for Dementia of the Consortium to Establish a Registry for Alzheimer's Disease. Am J Psychiatry. 1995;152:1349-1357.

41. Teri L, Truax P, Logsdon R, Uomoto J, Zarit S, Vitaliano P. Assessment of behavioral problems in dementia: the Revised Memory and Behavior Problems Checklist. Psychol Aging. 1992;7:622-631.

42. Wagner AW, Teri L, Orr-Rainey N. Behavior problems among dementia residents in special care units: changes over time. J Am Geriatr Soc. 1995;43: 784-787.

43. Burke WJ, Rubin EH, Morris JC, Berg L. Symptoms of 'depression' in dementia of the Alzheimer type. Alzheimer Dis Assoc Disord. 1988;2:356-362.

44. Cummings JL. Dementia and depression: an evolving enigma. J Neuropsychiatry Clin Neurosci. 1989;1:236-242.

45. Devanand DP, Sano M, Tang M-X, Taylor S, Gurland BJ, Wilder D, Stern Y, Mayeux R. Depressed mood and the incidence of Alzheimer's disease in the elderly living in the community. Arch Gen Psychiatry. 1996;53:175-182.

46. Mackenzie TB, Robiner WN, Knopman DS. Differences between patient and family assessments of depression in Alzheimer's disease. Am J Psychiatry. 1989;146:1174-1178.

47. Reifler BV, Teri L, Raskind M, Veith $R$, Barnes $R$, White E, McLean P. Doubleblind trial of imipramine in Alzheimer's disease patients with and without depression. Am J Psychiatry. 1989;146:45-49.

48. Bylsma FW, Folstein MF, Devanand DP, Richards M, Bello J, Albert M, Stern $Y$. Delusions and patterns of cognitive impairment in Alzheimer's disease. Neuropsychiatr Neuropsychol Behav Neurol. 1994;7:98-103.

49. Jeste DV, Wragg RE, Salmon DP, Harris MJ, Thal LJ. Cognitive deficits of patients with Alzheimer's disease with and without delusions. Am J Psychiatry. 1992;149:184-189. 